DOI: 10.1007/s11666-009-9399-x

\title{
Erratum to: From Particle Acceleration to Impact and Bonding in Cold Spraying
}

Tobias Schmidt, Hamid Assadi, Frank Gärtner, Horst Richter, Thorsten Stoltenhoff, Heinrich Kreye, and Thomas Klassen

\section{Erratum to: Journal of Thermal Spray Technology DOI 10.1007/s11666-009-9357-7}

The authors have notified the publisher of two errors in their article (appearing in this issue), relating to Figs. 13 and 19.

(1) The $\mathrm{x}$-axis of Fig. 13 label. As illustrated below, the axis should be titled "impact velocity $[\mathbf{m} / \mathbf{s}]$ ". In the caption and the text the word "temperature" should be replaced by "velocity" as follows:

"Figure 13 summarizes impact calculations performed for 5, 15, 25, 50 and $150 \mu \mathrm{m} \mathrm{Cu}$ particles, where the impact

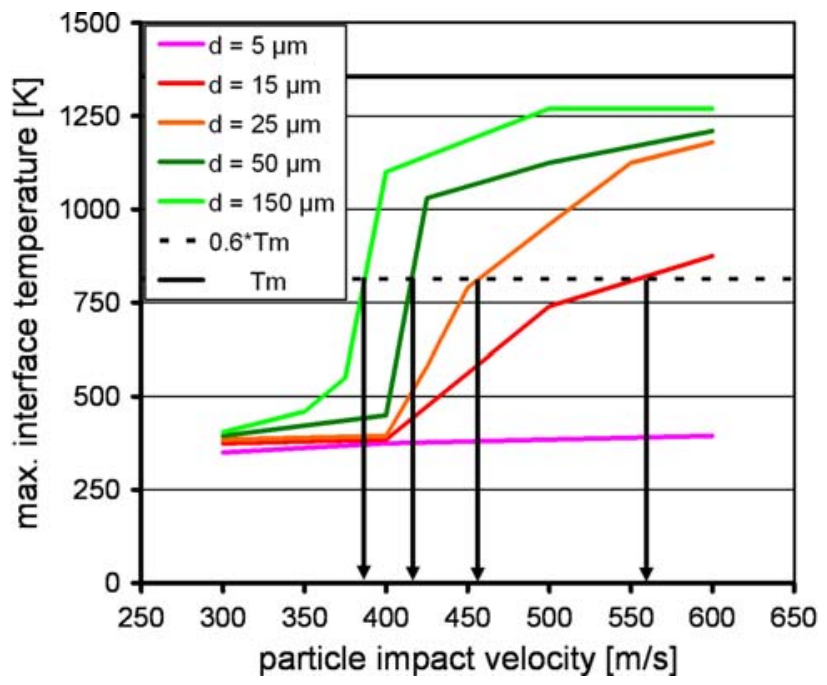

Fig. 13 Maximum of average interface temperature (compare with Fig. 12) at the monitored element (compare with Fig. 10) set as a function of particle impact velocity, plotted for different particle sizes velocity was varied in $50 \mathrm{~m} / \mathrm{s}$ steps from 300 to $600 \mathrm{~m} / \mathrm{s}$. The initial temperature of particles and the substrate material was constant at $20{ }^{\circ} \mathrm{C}$. This diagram shows the maximum interface temperature (compare with Fig. 12) of the monitored element set (compare with Fig. 10) as a function of the impact velocity for the different particle sizes. The more or less steep rise in interface temperature indicates the occurrence of shear instabilities.

(2) In the caption of Fig. 19, (a) and (b) were interchanged. The correct description is illustrated in the caption for Fig. 19.
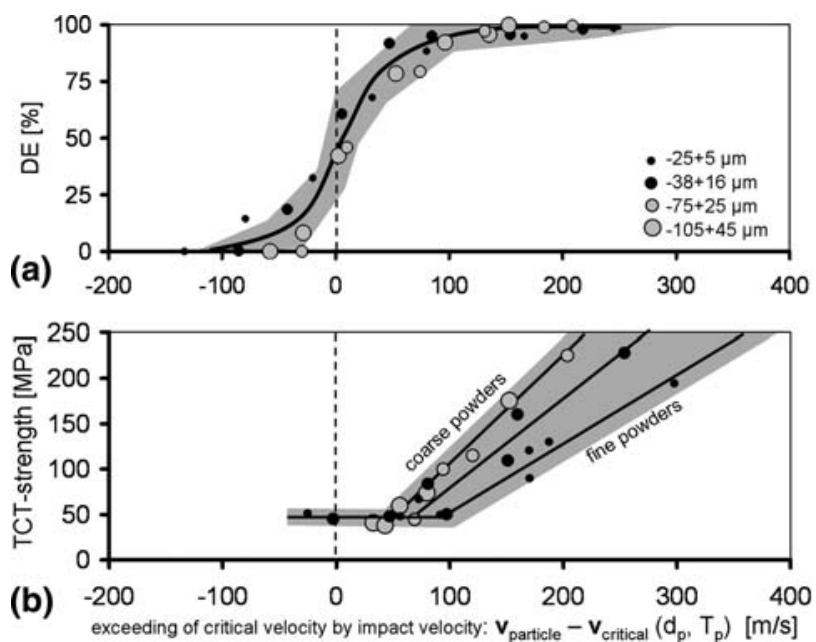

Fig. 19 Summary of spray experiments with four different powder size cuts and a variety of spray conditions showing size effects. (a) DE and (b) coating strength (TCT tests) as a function of exceeding the critical velocity by impact velocity. The velocities are calculated values according to Eq 4 and the onedimensional fluid dynamic model.

The online version of the original article can be found under doi:10.1007/s11666-009-9357-7.

Tobias Schmidt, Hamid Assadi, Frank Gärtner, Horst Richter, Thorsten Stoltenhoff, Heinrich Kreye, and Thomas Klassen, Helmut Schmidt University, Hamburg, Germany; Hamid Assadi, Tarbiat Modarres University, Tehran, Iran; Horst Richter, Thayer School of Engineering, Dartmouth College, Hanover, NH; and Thorsten Stoltenhoff, Praxair Surface Technologies, Ratingen, Germany. Contact e-mail: gaertner@hsu-hh.de. 